\title{
Téoros
}

Revue de recherche en tourisme

\section{Le tourisme au Nunavik}

\section{Claire Girouard}

Volume 17, numéro 2, été 1998

L'industrie touristique autochtone

URI : https://id.erudit.org/iderudit/1072271ar

DOI : https://doi.org/10.7202/1072271ar

Aller au sommaire du numéro

\section{Éditeur(s)}

Université du Québec à Montréal

\section{ISSN}

0712-8657 (imprimé)

1923-2705 (numérique)

Découvrir la revue

\section{Citer cet article}

Girouard, C. (1998). Le tourisme au Nunavik. Téoros, 17(2), 26-27.

https://doi.org/10.7202/1072271ar d'utilisation que vous pouvez consulter en ligne.

https://apropos.erudit.org/fr/usagers/politique-dutilisation/ 


\section{Le tourisme aU NunaVIK}

\section{Claire Girouard}

Le Nunavik, au nord du $55^{e}$ parallèle, est une région dont la superficie équivaut au tiers de la superficie totale du Québec. Environ 8700 Inuit y vivent dans quatorze villages le long des côtes de la baie d'Ungava et de la baie d'Hudson. Les populations locales varient de 150 habitants à Aupaluk à près de 2000 à Kuujjuaq, centre administratif de la région.

Aucune route ne relie le sud du pays au Nunavik. Le transport aérien y est assuré par First Air et Air Inuit, deux compagnies qui appartiennent aux Inuit du Nunavik. L'été, une compagnie maritime assure l'approvisionnement des communautés (matériaux de construction, pétrole, nourriture, entre autres).

La culture, l'isolement géographique et l'étendue du territoire sont des facteurs déterminants du développement touristique de la région.

\section{LA SITUATION ACTUELLE ET LES PROJECTIONS}

Les premières activités touristiques remontent aux années 1970 lorsque quelques entrepreneurs non autochtones ainsi que des Inuit, assistés par le ministère des Affaires indiennes et du Nord et la Fédération des coopératives du NouveauQuébec, ont ouvert quelques pourvoiries. Cependant, ce n'est qu'à partir de 1985 que les Inuit ont pris une part active au volet touristique, quand le gouvernement du Québec, dans le but de favoriser le développement économique et la participation autochtone, a facilité l'obtention de permis par les entrepreneurs d'origine Inuit et ceux qui s'associaient à des Inuit. Comme les activités de chasse et de pêche sont des occupations traditionnelles pour les Inuit, il était tout à fait naturel pour ces derniers de participer à un tel aspect du développement touristique.

Ainsi, en 1998, les Inuit sont soit propriétaires, soit actionnaires majoritaires
$(51 \%)$ des dix-sept pourvoiries du Nunavik. La plupart des pourvoiries sont exploitées en partenariat : le ou les partenaires non autochtones assument toutes les fonctions administratives, la mise en marché et la représentation ; la tâche des Inuit se limite souvent à la gestion du camp, rôle qui est appelé à changer, car la relève, davantage instruite, voudra sans nul doute prendre part à tous les aspects de l'entreprise familiale.

Le Nunavik a un réseau de pourvoiries très bien structuré, ce qui lui donne, à cet égard, une longueur d'avance sur les autres régions du Québec. Selon le ministère de l'Environnement et de la Faune, les pourvoyeurs ont déclaré en 1997 de revenus d'environ quatre millions de dollars. Plus de 2500 chasseurs et pêcheurs - en grande majorité Américains - visitent le Nunavik de juillet à octobre. Le coût des forfaits varie de $3500 \$$ à $5000 \$$ can. et les retombées économiques sont de l'ordre 10 millions de dollars.
Ce segment de l'industrie a en quelque sorte façonné le produit touristique actuel et assure ainsi un revenu pour le Nunavik. Dans un tel contexte, il est fort important d'apporter un soutien à ce volet de l'industrie sans toutefois négliger les autres produits qui sont présentement au stade de développement, notamment le tourisme culturel, écologique, de plein air et d'aventure.

Le Nunavik a beaucoup à offrir. La culture Inuit, particulièrement, à la fois moderne et traditionnelle, est l'un des aspects les plus intéressants de la région et lui donne sa spécificité. Des ressources naturelles de qualité foisonnent : un troupeau de plus d'un million de caribous, des bœufs musqués, des ours polaires, ainsi que des mammiferes marins tels que le béluga, le morse et le phoque. Les attraits touristiques sont exceptionnels : les monts Torngats, le cratère du NouveauQuébec, le lac Guillaume-Delisle, les îles Digges, sans parler des rivières qui offrent des défis fort intéressants aux amateurs de kayak et de canoë.

Cependant, le développement des activités touristiques se bute à des obstacles de taille dont le plus important est sans aucun doute le coût. Au départ de Montréal, un forfait d'une semaine au Nunavik coûte au moins $3000 \$$ et il faudra compter un minimum de $4000 \$$ pour les villages plus au nord du territoire. En effet, comme aucune route ne relie le Nunavik au reste du pays, le prix augmente d'autant que l'accessibilité diminue. Le transport aérien est dispendieux et le coût de la vie au Nunavik est très élevé. En outre, le marché étant très restreint, on ne peut certes pas compter sur le volume pour faire baisser les prix. 
Divers facteurs font qu'il est difficile d'intéresser des entrepreneurs ou même des communautés à développer ce genre d'activités : le climat qui n' intéresse que quelques irréductibles, le financement difficile à obtenir par les petites entreprises, le manque de qualifications des guides, la courte période d'activités, l'absence de pares provinciaux et un budget de promotion limité.

On trouve au Nunavik un aspect touristique particulier à la région : le tourisme d'affaire. En raison de sa situation géographique, culturelle et politique, le Nunavik accueille en effet chaque année, dans différents villages de la région, audelà de 3000 personnes pour des séjours de trois à cinq jours. Il s'agit là d'un volet touristique qu'il reste à exploiter.

\section{L'APPROCHE TOURISTIQUE}

Le tourisme étant devenu une réalité, il était impératif que le Nunavik se dote d'une association touristique régionale. Ainsi, en 1997, l'Association ouvrait un bureau à Kuujjuaq et obtenait de l'aide financière (du gouvernement québécois ainsi que d'organismes régionaux tels que la société Makivik, l'administration régionale Kativik, les compagnies de transport First Air, Air Inuit et Desgagné), ce qui lui a permis de poursuivre le travail amorcé.

La majorité du personnel, des membres de l'Association et du Conseil d'administration sont Inuit et habitent le Nunavik, ce qui assure l'engagement et l'intérêt des membres, des organismes régionaux et de la population en général.

Une des premiềres actions prises par l'Association touristique a été l'ellaboration d'un plan de développement stratégique. En outre, un inventaire des produits, des capacités d'hébergement et des possibilités de développement a été effectué afin de bien orienter les développements futurs ainsi que l'approche de mise en marché. Les démarches ont abouti au plan d'action suivant.

A court et moyen terme :

- consolidation du produit chasse et pêche et diversification des produits ;

- développement de produits culturels et d'aventure:

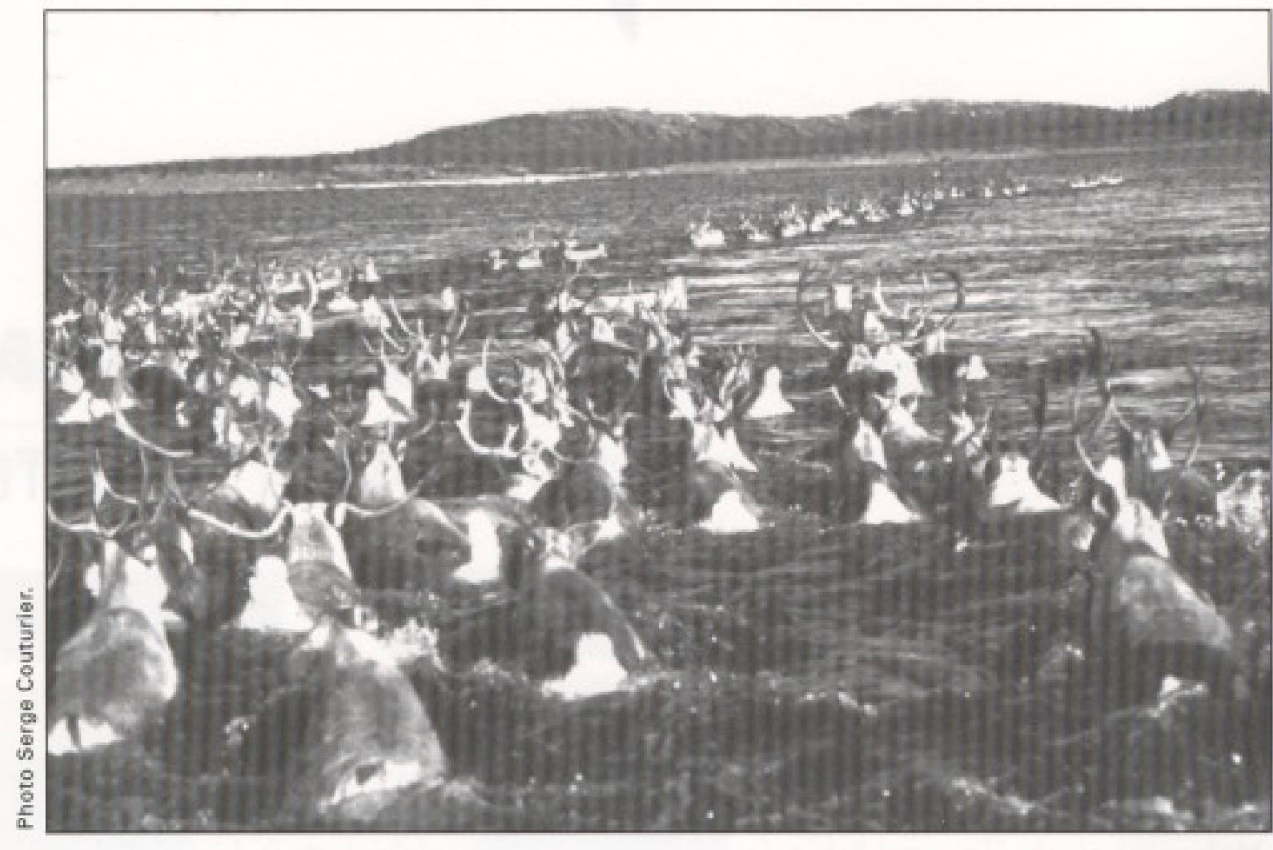

- développement de produits court terme pour le tourisme d'affaire.

A long terme :

- développement de produits haut de gamme.

\section{LA PARTICIPATION DES INUIT ET LEUR POSITION}

Si l'on se fie au nombre d'Inuit actionnaires des pourvoiries, à leur participation au Conseil d'administration de l'Association, à la contribution financière des deux organismes les plus importants du Nunavik — la société Makivik et l'administration régionale Kativik -, à l'aide des compagnies aériennes First Air et Air Inuit, il $y$ aurait un engagement certain dans le processus de développement.

Pourtant, en ce qui a trait à la population en général, les commentaires recueillis lors de la dernière tournée dans les villages (dans le cadre du plan de développement stratégique) démontrent un intérêt mitige : certains y voient une avenue de développement économique intéressante qui pourrait être génératrice d'emplois alors que d'autres y voient peu d'intérêt ou n'y croient pas beaucoup. Cependant, un consensus demeure : les Inuit sont fiers de leur culture et de leurs traditions et tous sont prêts à les partager et à les faire connaître.

\section{L'IMPORTANCE DU DÉVELOPPEMENT TOURISTIQUE DANS LE MILIEU INUIT}

Le développement touristique a une grande importance pour les Inuit, mais pas à n'importe quel prix. Les Inuit sont soucieux de la façon dont se fera le développement et sont très concernés par les aspects suivants :

- ils veulent garder un contrôle sur le rythme de développement et ses conséquences sur l'environnement ;

- ils veulent s'assurer d'une formation appropriće et adaptée à leur environnement culturel particulier ;

- ils veulent, plus que tout, prendre en main le développement économique de leur région et assurer la création d'emplois pour les générations futures.

Claire Girouard travaille pour les Inuit du Nunavik depuis 1976. Durant cette période, elle a eu l'occasion de vive et de voyager sur un territoire encore peu connu. Depuis deux ans, elle coordonne la mise sur pied de l'Association touristique du Nunavik, nouvellement créée.

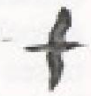

